\title{
Ontogeny of GnRH systems
}

\author{
M. Caldani ${ }^{1}$, M. Antoine ${ }^{1}$, M. Batailler ${ }^{1}$ and A. Duittoz ${ }^{2}$ \\ ${ }^{1}$ INRA, PRMD, Neuroendocrinologie Sexuelle, F37380 Nouzilly, France; and ${ }^{2}$ Université de Tours, \\ Faculté des Sciences et des Technologies, Neuroendocrinologie, Parc de Grandmont, F37200 Tours, \\ France
}

\begin{abstract}
In all vertebrate species studied, the main central population of GnRH neurones, which produces the final messages regulating reproduction, originates outside the brain. Early during fetal life, they appear in the olfactory placode epithelium and then migrate toward the base of the telencephalon in close association with the nervus terminalis, penetrate the brain within the nervus terminalis roots, reach their final locations and eventually grow axons toward their targets. Only part of this process is documented in ruminants. In the sheep fetus, the olfactory placode develops between day 22 and day 26 of gestation, but the first GnRHimmunoreactive neurones have been detected only at day 35, associated with the extracerebral part of the nervus terminalis. During the next 30-40 days, the GnRH neuronal systems progressively invade the brain. In both sexes, most of the development, in terms of distribution and morphology of the neurones, appears to be completed by the middle of gestation (term being on day 145). On day 85 $\mathrm{GnRH}$-immunoreactive neuronal systems of male and female fetuses have also been reported to be very similar to GnRH neuronal systems of adult females. Attention should now be focused on the earliest developmental steps.
\end{abstract}

\section{Introduction}

For each animal, reproduction is a key task involving numerous neural, endocrine and behavioural events. Most of the endocrine events are controlled by the rate of secretion into the hypothalamopituitary portal blood of a single decapeptide, gonadotrophin-releasing hormone (GnRH). Some of the sexual behavioural components may also require the expression of $\mathrm{GnRH}$-linked information. Therefore, GnRH pulsatile secretion is to some extent the final common message from the brain, integrating all the neurally translated cues necessary for reproduction to occur (for a review, see Caldani et al., 1993). Besides this rhythmic activity, implying the existence of a pace-maker and of a way of synchronizing about two thousand neurones, the $\mathrm{GnRH}$ neurones possess a unique property as neuroendocrine neurones; i.e. they originate outside the brain.

In adult ruminant brains, as in all eutherian mammals studied in detail (see Silverman et al., 1994), the GnRH neurones are not found in precise groups of cells but occur as a loose continuum in the ventral telencephalic and diencephalic areas (sheep; Advis et al., 1985; Lehman el al., 1986; Caldani et al. 1988; cows: Leshin et al., 1988). Figure I shows the distribution of the 2500-3000 GnRH immunoreactive neurones of an adult sheep brain (half of them being found in the preoptic area), and the main fibre pathways and terminal fields (Caldant et al., 1988). GnRH-immunoreactive neurones are also found outside the brain: since the pioneering work of Schwanzel-Fukuda and Silverman (1980) describing the presence of GnRH-immunoreactive neurones in the nervus terminalis of adult guinea-pigs, the same localization has also been found in numerous species (see Silverman et al., 1994) including sheep (Caldani et al., 1987). For a general review of the nervus terminalis complex and its possible functions see Demski (1993). 


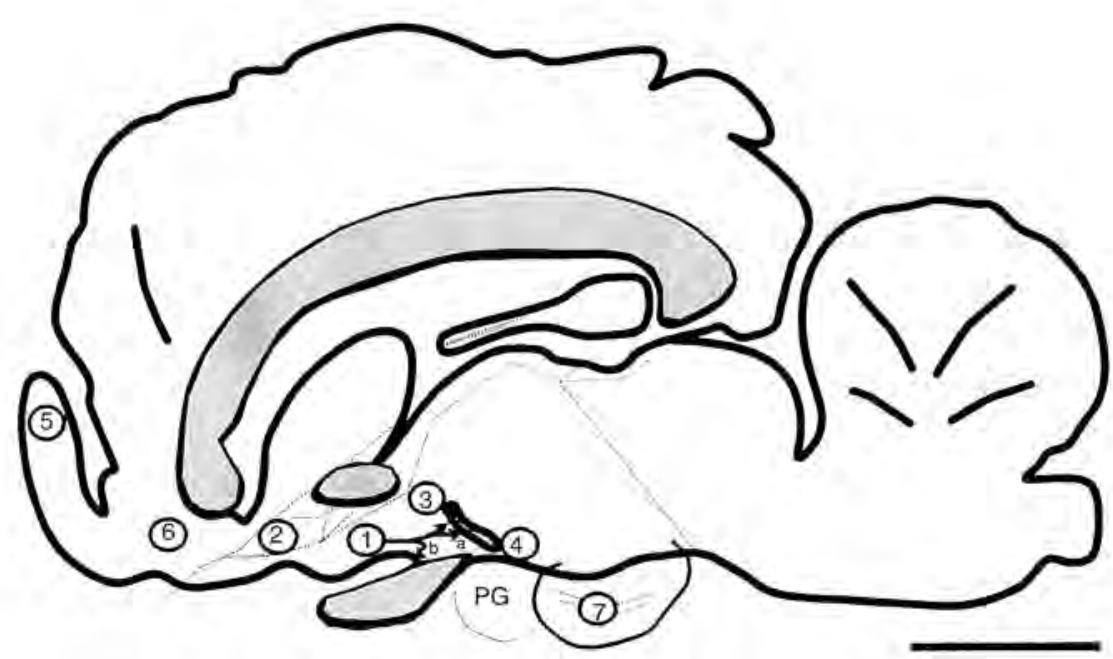

Fig. 1. Schematic drawing of a sagittal projection of an adult sheep brain with the location of GnRH-immunoreactive perikarya: (1) preoptic area (50\%). (2) olfactory tubercle/septal area $(15 \%)$, (3) anterior and lateral hypothalamus (16\%), (4) mediobasal hypothalamus $(14 \%)$ and extrahypothalamic structures (5\%): olfactory bulb (5), subcallosal area (6) and median amygdala (7). Major projection sites are (a) median eminence and (b) organum vasculosum of the lamina terminalis. Dotted lines represent $\mathrm{GnRH}$-immunoreactive fibres. PG: pituitary gland. Scale bar represents $1 \mathrm{~cm}$.

Determining how the diffuse system of individual, scattered neurones is coordinated in the adult brain will be "... one the major anatomic challenges of this decade" (Silverman et al, 1994), but the challenge of the last few years has been to demonstrate that the $\mathrm{GnRH}$ neurones originate outside the brain at the olfactory placode and then migrate into the brain, in close association with the nervus terminalis system. Such a phenomenon was first described in the mouse fetus (Schwanzel-Fukuda and Pfaff. 1989; Wray et al. 1989a,b), and then in other species, suggesting that it is a general phenomenon among vertebrates.

The different steps of the ontogeny of the GnRH systems will be described and discussed in the following sections, on the basis of available data in vertebrates. Special attention will be paid to what is known in ruminant species (i.e. sheep), based mainly on our own work.

\section{Origin of GnRH Neurones}

\section{General embryology}

During the early stages of vertebrate embryo development, the sensory placodes appear as thickenings of the head epiderm. Later, the olfactory placode invaginates twice: the first (main) recess later develops into the nasal cavity; the secondary (accessory), medial recess becomes the vomeronasal organ. From the lateral part of the olfactory epithelium neurones associated with the main olfactory system migrate, whereas neurones associated with the accessory (vomeronasal) system migrate from the medial part of the epithelium. The neurone migrations from the rat olfactory placode have been investigated in detail (Pellier and Astic, 1994). Another neuronal system, the nervus terminalis, also originates in the epithelium of the secondary recess, and migrates toward the posterior forebrain in the medial septum and preoptic area (Johnston, 1913; Larsell, 1918, 1950).

\section{First appearance of GnRH-immunoreactive neurones}

The mouse fetus has been a 'model of choice' for the description of GnRH neurones in the 
epithelium of the medial part of the olfactory placode (Schwanzel-Fukuda and Pfaff, 1989; Wray et al., $1989 \mathrm{a}, \mathrm{b})$, as in mice the phenotypic differentiation, i.e. GnRH synthesis, allows them to be observed directly before they begin to migrate. Such a direct observation has also been reported in Rhesus monkey fetuses (Ronnekleiv and Resko, 1990) and in some non-mammalian species (chicken: Norgren and Lehman, 1991; Murakami et al., 1991). However, in most vertebrates, there is evidence of a close association between GnRH neurones and elements of the nervus terminalis during the later stages of development (for reviews, see Tobet et al., 1992; Daikoku et al., 1993; Silverman et al., 1994). This evidence has been corroborated both by studies in which the ablation of the olfactory placode was followed by the absence of GnRH-immunoreactive neurones (in amphibians: Murakami et al.; 1992; Northcutt and Muske, 1994 or in chicken: Akutsu et al., 1992), and studies showing the presence of GnRH-immunoreactive neurones in cultures derived from mouse (Schwanzel-Fukuda et al., 1992b), monkey (Terasawa et al., 199.3) and rat (Daikoku et al., 1993) olfactory placodes in vitro. In rats, this result is of great importance since, in that species, GnRH-immunoreactive neurones were never directly labelled at the placode epithelium.

The previous data clearly show that there may be differences in the rate of GnRH synthesis in the earliest steps of the development among species, which could determine whether GnRH-immunoreactive neurones could be detected in the olfactory placode epithelium. On paraffin wax sections obtained from ovine fetuses and stained with cresyl violet for topographical recognition, we identified the first appearance of the olfactory placode as a thickening of the nasal epiderm (Fig. 2a) on day 22. It then invaginates twice, and by day 26 the two recesses, the main one and the accessory one on its medial side, are clearly obvious in horizontal sections (Fig. 2b). At this stage, groups of cells associated with fibre bundles can be distinguished between the epithelium of the placode and the base of the forebrain (Fig. 2c). As the recess deepens, the turbinates develop and become evident between day 29 and day 35 . On paraffin-wax sections, GnRH-immunoreactivity was not observed before day 52 . The sensitivity of immunodetection was increased by investigating cryostat sections from days 26 to 35 (the period when nasal cavity development occurs) fetuses for GnRH immunohistochemistry, but we could not label any GnRH-immunoreactive neurones before day 35 , and we did not find them in the epithelium. Determining whether the presence of GnRH-immunoreactive neurones inside the epithelium of the olfactory placode represents real species differences or whether it is related to the nature of the epitopes recognized by the primary antibodies used is currently under investigation. On fetal sheep tissue the anti-2-10 GnRH antibody we use, which recognizes only the free peptide (Caldani et al., I988), is different from the antibody used in the mouse studies (see Livne et al., 1993 for the differential kinetics in the development of the peptide and its precursor immunoreactivities in the fetal mouse).

\section{Placode or not placode?}

In the chick embryo, the removal of the olfactory placode anlage at a stage as early as the neural folds stage is not followed by the absence of GnRH-immunoreactive neurones (El Amraoui and Dubois, 1993). Rather, GnRH neurones were not detected when the presumptive ectoderm of the nasal cavity or both the olfactory placode and the ectoderm of the nasal cavity presumptive territories were removed. Thus, in the chick embryo, GnRH neurones seem to be committed very early during development and, moreover, they do not originate from the olfactory placode but from the adjacent ectoderm of the nasal cavity presumptive territory ( $\mathrm{El}$ Amraoui and Dubois, 1993), close to the presumptive territory of the adenohypophysis (Couly and Le Douarin, 1988). As olfactory placode ablation at later stages of development in chicken (Akutsu et al., 1992) or in newts (Murakami et al., 1992) results in a failure of GnRH neurone development, it is hypothesized that a first migration occurs early during neurogenesis and that ".. olfactory placode derivatives (i.e. olfactory epithelium and nerve) should be regarded as a bridge, but not as a source, for GnRH neurones to reach brain areas" (El Amraoui and Dubois, 1993).

In addition to the main GnRH neurone group, the 'terminalis group' or GnRH-I group, which is always found as a continuum in tel-and di-encephalic structures, a second group of GnRH neurones has been described in several vertebrates (see Northcutt and Muske, 1994), this group being more caudally and not anatomically contiguous with the GnRH-I group (GnRH-II group). The question of the origin of the GnRH-II neurones has recently been posed: in the axolotl, bilateral olfactory placode ablation, followed by the disappearance of the GnRH-1 group, is not followed by the disappearance of the 

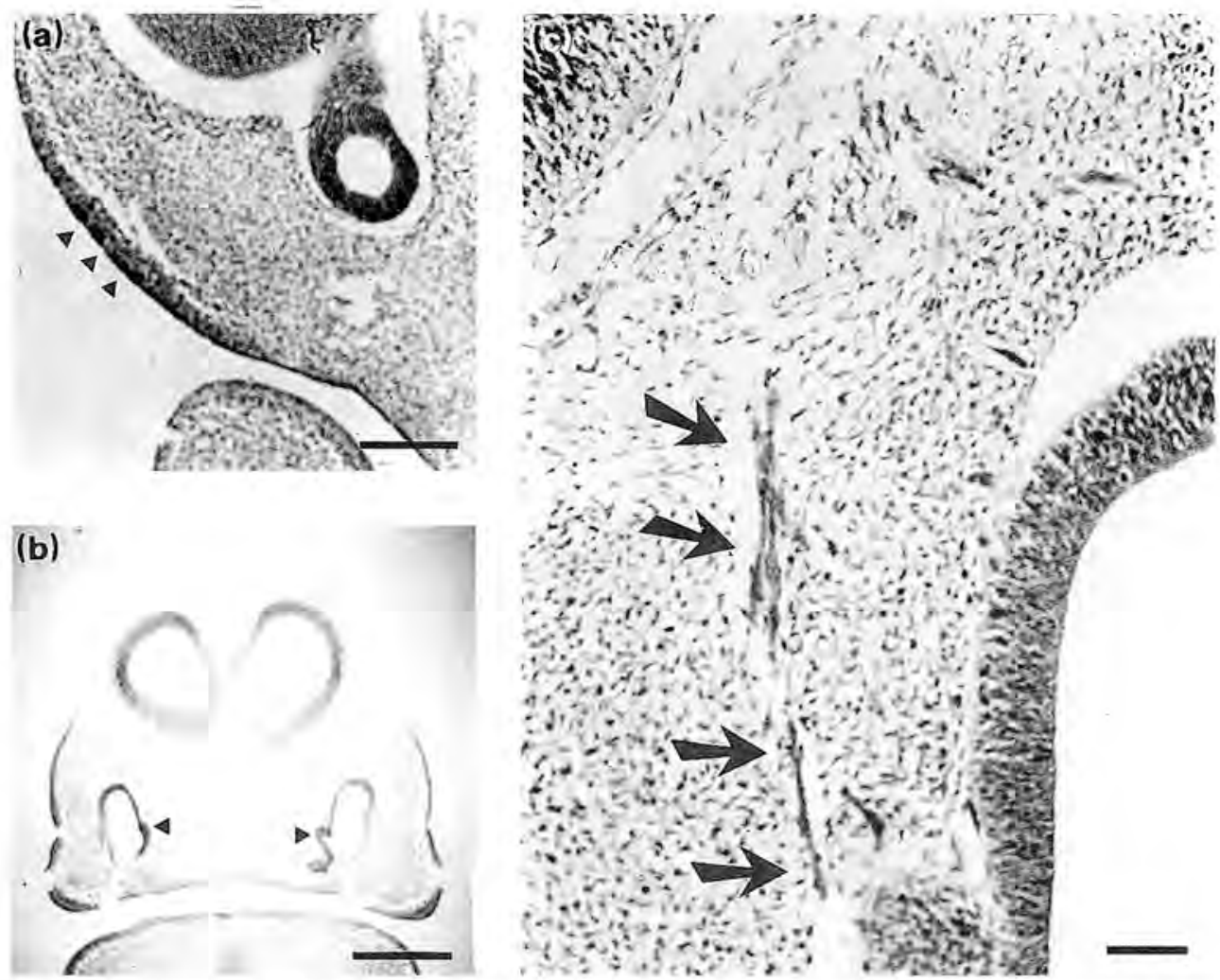

Fig. 2. Development of the olfactory placodes of sheep fetus on cresyl violet stained paraffin-wax sections. (a) Day 22 fetus, sagittal view, the olfactory placode is a small thickening of the face epiderm (arrowheads); (b) and (c) day 26 fetus, horizontal view, the main and accessory (arrowheads) recesses of the placode are present (b), with fascicles of cells (arrows) between the olfactory epithelium and the ventral forebrain (c). Scale bars represent $1 \mathrm{~mm}$ in (a) and (b), and $100 \mu \mathrm{m}$ in (c).

GnRH-II group, which, therefore, is not of nasal origin (Northcutt and Muske, 1994). Moreover, the recently characterized frog GnRH-I gene shares common features with the mammalian gene but is not responsible for the expression of $\mathrm{GnRH}$ in the caudal group (Hayes et al., 1994).

It can be concluded that two populations of GnRH neurones coexist in the brain of vertebrates, one of placodal/ectodermal origin, responsible for the gonadotrope function, and the other one of unknown origin, responsible for an unknown function, synthesizing a GnRH-related peptide(s), encoded by an unknown gene. However, no data are available about the GnRH-II group in sheep.

\section{Extracerebral Migration of GnRH Neurones}

After appearing in the epithelium of the olfactory placode, the GnRH neurones migrate from the nasal cavity through the cribriform plate, follow the intracranial course of the nervus terminalis and penetrate the brain within its roots.

\section{Kallmann syndrome}

In humans, an association of anosmia and hypogonadism, known as the Kallmann syndrome (Kallmann et al., 1944), is considered to result from the failure of olfactory and GnRH neurones to migrate into the brain normally (Schwanzel-Fukuda et al., 1989). The human Kallmann gene has been shown to encode a putative adhesion protein (Legouis et al., 1991, 1994). Furthermore, its chicken 
homologue is expressed in both fetal and adult mitral cells of the olfactory bulbs (the targets of the olfactory axons), suggesting a role in neuronal targeting for the encoded protein, the failure of the $\mathrm{GnRH}$ neurone migration being a consequence of the abnormal development of the olfactory bulbs (Rugarli et al., 1993).

\section{Cell adhesion molecules (CAMs) and migratory mechanisms}

The mechanisms involved in this migration remain largely unknown, In chick embryos, an association between neural cell adhesion molecule (NCAM)-immunoreactive cells and GnRH migrating neurones has been described (Murakami et al., 1991; Norgren and Brackenbury, 1993). However, the precise role of NCAM in migration is not clear. As NCAMs are expressed uniformly in the olfactory epithelium and nerves, without increased intensity of staining in the vicinity of GnRH neurones, it has been suggested that rather than guiding the migration, they could play a permissive role (Norgren and Brackenbury, 1993). Similarly, in the mouse fetus, GnRH-immunoreactive neurones have been shown to follow a type of scaffolding made of NCAM-immunoreactivity which joins the olfactory epithelium to a cellular aggregate located below the forebrain, where GnRH-immunoreactive neurones are observed before they penetrate the brain (Schwanzel-Fukuda et al, I992a). Moreover, antibodies to NCAM, when injected at the level of the olfactory recess before the onset of migration, can disrupt the migration of GnRH neurones (Schwanzel-Fukuda et al., 1994). Lastly, neurones expressing NCAM along the migration route between the olfactory placode and the forebrain in Rhesus monkey fetuses have also been shown to express a non-mammalian (not yet identified) form of $\mathrm{GnRH}$, preceding and maybe providing guiding cues for the mammalian neurones expressing GnRH (Quanbeck et al., 1994). Other challenging molecules could also play a role in migration, for example a glycoconjugate, CC2, which is expressed intensely at the cribriform plate (Tobet et al., 1992), or the growth-associated protein GAP-43 (Livne et al, 1993).

\section{Role of the GnRH neurones in their own migration}

In addition, the direct involvement of the GnRH neurones in migration has been shown by the disruption of migration in mice transgenic for the GnRH gene (Radovick et al., 1991).

\section{Do GnRH-immunoreactive neurones also migrate in the sheep fetus?}

Owing to the low sensitivity of GnRH immunohistochemical detection methods on paraffin-wax sections, sheep fetus cryostat sections were treated in the presence or absence of Triton-X100.

Examination of cryostat sections immunohistochemically treated without Triton-X100 obtained from day 29-35 fetuses did not reveal any immunoreactive structures and from day 36, all the GnRH immunoreactivity was found exclusively inside the brain.

The main observation of the cryostat sections treated in the presence of Triton-X100 was the appearance of $\mathrm{GnRH}$ immunoreactivity earlier than in the other groups and its occurrence outside the brain. The specificity of the immunoreaction was assessed by its absence after preincubation of the primary anti-GnRH antibody with mammalian GnRH, but not with chicken I- or chicken II-GnRH. Although no labelling was demonstrated on day 29 , from day 35 immunoreactive cells were present in the head and neck epidermis (Fig. 3a). This labelling persisted throughout gestation and during adulthood (Caldani and Batailler, 1990). As early as day 36 (data not shown), it was also possible to detect some immunoreactive neurones and fibres both in the nervus terminalis and in the medial olfactory tubercle, where the nervus terminalis has been shown to penetrate the brain in adults (Caldani et al., 1988). GnRH-immunoreactive structures were never observed in the nervus terminalis without any labelling inside the brain.

$\mathrm{GnRH}$ immunodetection was also performed on free-floating sections obtained from a day 40 fetus. As on cryostat sections in the presence of Triton-X100, immunoreactive cells were simultaneously labelled in the facial and neck epiderm (Fig. 3b) and in the upper part of the posterior nasal cavity, at the level of the intranasal course of the nervus terminalis (Fig. 3c). 

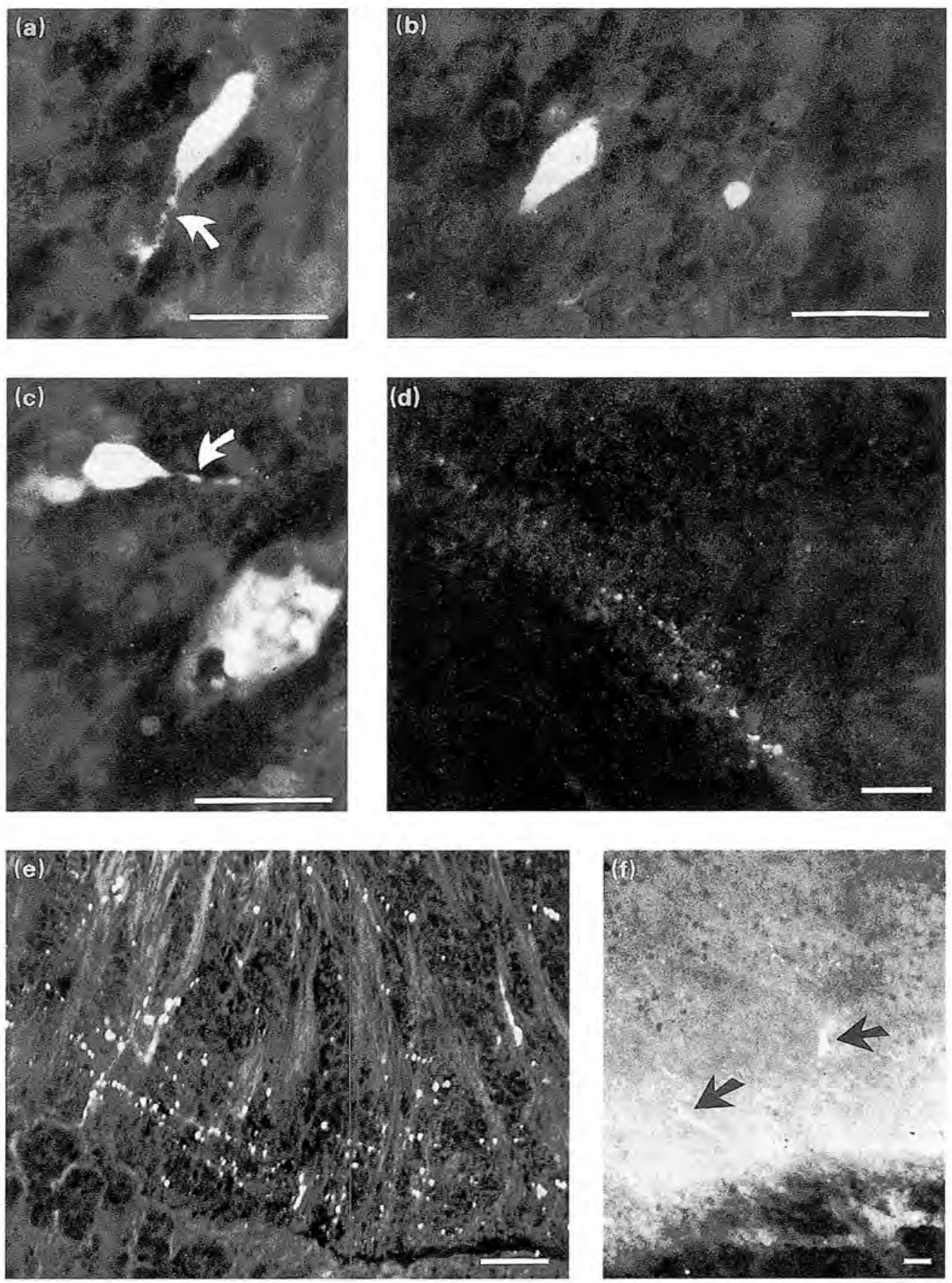

Fig. 4. Classical immunofluorescence methods (overnight incubation in the primary antibody and I h incubation in the secondary antibody, both being diluted 1/200) show that GnRH-immunoreactive structures are very weakly labelled on the paraffin-wax sections and cryostat sections without Triton-X100 from sheep fetuses at very early stages. However, on paraffin-wax sections, perikarya appear to be labelled in the preoptic (a), septal (b) and anterior hypothalamic (c) areas, with few immunoreactive fibres starting from the perikarya (arrows) and terminals in the organum vasculosum of the lamina terminalis (d) in a fetus at day 63. From day 80 , no more immunoreactive perikarya are labelled on paraffin-wax sections, but the number of immunoreactive fibres increases until birth, especially in the median eminence (day 141 (e)). Numerous immunoreactive perikarya (arrows) and fibres are also found in the mammillary bodies (day 62, cryostat (f)). Scale bars represent $25 \mu \mathrm{m}$. 
organum vasculosum of the lamina terminalis, or more laterally, near the anterior commissure and in the medial septum (Fig, 4b). Some of them were more posteriorly located in the anterior and lateral hypothalamus (Fig. 4c). In one case (day 63) one immunoreactive perikaryon was identified in the infundibular nucleus.

On day 52 , immunoreactive perikaya were labelled exclusively in the preoptic area, very close to the lamina terminalis. Later, their distribution and number increased; about $20-50$ on day 52 , between 250 and 300 on day 63 and between 1500 and 2000 on day 70 . These numbers were estimated from the numbers of perikarya labelled on the one treated section of every ten sections. The observed distribution differed from that of adults; the proportion of immunoreactive perikarya in the infundibular nucleus was smaller and the posterior extension of cellular labelling was larger as it includes the mammillary bodies (data not shown).

Immunoreactive fibres and terminals were first mainly concentrated in the preoptic area and organum vasculosum of the lamina terminalis (Fig. 4d), respectively. Later, in the mediobasal hypothalamus, fibres showed a preferential orientation toward the median eminence which itself remained quite devoid of any labelling until day 70 .

It was not possible to observe even one immunoreactive perikaryon on fetuses at day 80 or later. Conversely, the number of immunoreactive fibres and terminals increased both in the preopticohypothalamic areas and extra-preopticohypothalamic areas. At the median eminence they were rapidly organized with the same pattern as in the adult: their highest concentrations were observed in the dorsolateral parts of the external layer (Fig. 4e).

Cryostat sections without Triton-X100. The first GnRH-immunoreactive structures were observed between day 36 and day 40 . Owing to the weak intensity of labelling, no difference was noticed between day 40 and day 43 . Immunoreactive neurones, always very scarce at this stage of development, were found in the olfactory tubercle and in the basal preoptic, septal and lateral hypothalamic areas. Fibres were also labelled in the mediodorsal preoptic area and the mediobasal hypothalamus. The organum vasculosum of the lamina terminalis contained few, if any, fibres and the median eminence never contained them (data not shown).

Subsequently, immunoreactive perikarya progressively invaded the different parts of the preopticohypothalamic areas between day 49 and day 62 , including, as also noticed on paraffin-wax sections, the mammillary bodies (Fig, 4f).

Extra-hypothalamic GnRH-immunoreactive cells were quite difficult to detect, perhaps because there are few of them. However, very weakly labelled perikarya were observed in the medial amygdala on day 54 and in the olfactory bulbs on day 57 (data not shown), indicating a simultaneous development of $\mathrm{GnRH}$ systems in both preopticohypothalamic areas and extra-preopticohypothalamic groups.

The development of GnRH-immunoreactive fibres in the preopticohypothalamic areas was mainly the same as that of cell bodies. Between day 43 and day 49 , the immunoreactive fibres very quickly invaded all the parts of this region and presented a pattern of organization very similar to that observed in young or adult sheep. Conversely, their development at the median eminence was more progressive: fibres approached the lateral parts of this organ on day 49 , but they were rare. Their number increased progressively, but a concentration of fibres and terminals in the laterodorsal parts of the external layer was not obvious before day 66. The pituitary stalk did not contain GnRH fibres until day 97.

In extra-preopticohypothalamic areas containing GnRH-immunoreactive cell bodies, the development of immunoreactive fibres occurred between day 49 and day 83 .

In extra-hypothalamic regions that did not contain $\mathrm{GnRH}$-immunoreactive cell bodies, immunoreactive fibres seemed to develop progressively starting from the cells in the preopticohypothalamic area. For instance, fibres reached the stria medullaris thalami as early as day 62 , but the fasciculus retroflexus did not show labelling up to day 123.

Cryostat sections with Triton-X100. On day 40 the distribution of GnRH-immunoreactive neurones was limited to the medial olfactory tubercle and the anterior septum (Fig. 5a). 

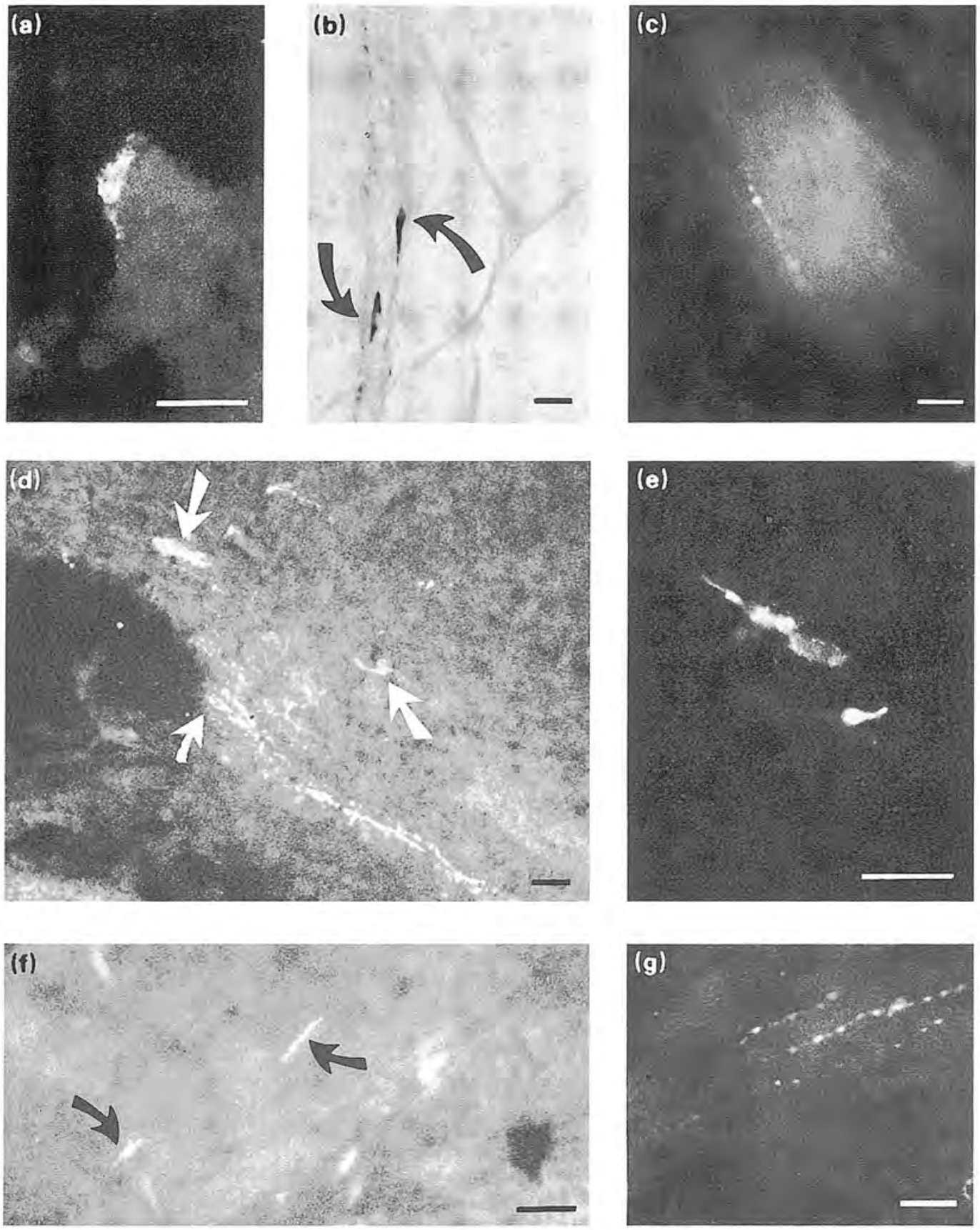

Fig. 5. In sheep fetuses from the cryostat sections with $1 \%$ Triton- $\mathrm{X} 100$ added to the primary antibody dilution, the first GnRH-immunoreactive structures inside the brain appear to be labelled at the entrance of the forebrain ((a), day 40). On day 49, while both GnRH-immunoreactive perikarya (arrows) and fibres are still present in the intranasal (b) and intracranial (c) parts of the nervus terminalis, they are also found in the mediobasal preoptic area (d) and in the septum (e). Few immunoreactive fibres (arrows) are labelled in the median eminence at that stage ( $\mathrm{f}$ ) but the number of fibres en route to the median eminence increases soon after, as illustrated by the presence of immunoreactive fibres along the lateral suprachiasmatic pathway on day $57(\mathrm{~g})$. Note that in (b) the fluorescent secondary antibody was replaced by a peroxidase-labelled antibody; the peroxidase activity was then revealed as in Fig. 3(a)-(c). Scale bars represent $25 \mu \mathrm{m}$. 
In fetuses at day $49, \mathrm{GnRH}$ immunoreactivity was found in similar locations to those in adult sheep that is from front to back, nervus terminalis (both in its intranasal, Fig. $5 \mathrm{~b}$ and intracranial, Fig. 5c parts), olfactory tubercles, preoptic (Fig. 5d) and septal (Fig. 5e) areas, hypothalamus, stria medullaris thalami, stria terminalis, habenula, fasciculus retroflexus and interpeduncular nuclei. In two major areas of adult brains that contain $\mathrm{GnRH}$, the olfactory bulbs and the periventricular central grey matter, no labelling was detected. At the median eminence (Fig. $5 f$ ) immunoreactive fibres to $\mathrm{GnRH}$ were very scarce. Later, the number of fibres en route to the median eminence increased regularly as illustrated by the presence of immunoreactive fibres along the lateral suprachiasmatic pathway on day 57 (Fig. $5 \mathrm{~g}$ ). In a 60 -day-old fetus, from which the most anterior and most posterior parts of the brain were not studied, the general distribution of $\mathrm{GnRH}$-immunoreactive elements was very close to that observed in adults (Fig. 6), with three exceptions: the proportion of immunoreactive cell bodies in the laterobasal preoptic area appeared to be greater than in adults, immunoreactive neurones were found in the mammillary bodies, and although immunoreactive fibres were present in the median eminence they were not concentrated mainly in its external zone.

Free-floating sections. On free-floating sections from fetuses at day 75 and day 111, the distribution of GnRH-immunoreactive structures inside the brain was similar to that observed in adult sheep: Moreover, as early as day 75 , the differences in morphology of the GnRH-immunoreactive perikarya, with unipolar, fusiform or multipolar shapes, as well as the presence of small clusters of neurones, typical of sheep GnRH-immunoreactive neurones (Lehmann et al,, 1986; Caldani et al, 1988; Wood et al, 1992), were observed (Fig. $7 \mathrm{a}-\mathrm{c}$ ).

Thus, the main result from our studies on sheep fetuses is that, even if the duration of gestation in sheep is 145 days, compared with 21-22 days in rodents, the development of the GnRH systems in the sheep fetus occurs during a short period, between about day 25 in the olfactory placode and about day 60 for the major components of the system to be distributed throughout the brain. In addition, the characteristic morphology of sheep GnRH neurones was observed as early as day 75 . This observation, together with an absence of sex differences also noticed in our studies (whenever both male and female fetuses of the same ages were available and processed with the same method, no sex difference was observed), has also been reported in a previous study of sheep fetuses at day 85 (Wood et al., 1992). Thus the full morphological maturation of the GnRH system seems to be completed before or around mid-gestation.

From the results obtained with paraffin-wax sections, it may be hypothesized that an increase in the synthesis or processing rate of GnRH or of both processes occurs from day 52, leading to an increased storage of the peptide in the perikarya. Thus, being above the sensitivity threshold of the method, some of the perikarya are labelled. Later, as axonal transport increases, or terminal release begins at the median eminence (about day 70), the perikarya storage decreases below the sensitivity threshold. This occurs not only during the second half of gestation but also during youth and adulthood, times when colchicine injections are required for labelling $\mathrm{GnRH}$ perikarya on paraffin-wax sections (Caldani et al., 1988).

The extension of the GnRH-immunoreactive cell bodies is larger in fetuses than in young or adults, especially with the presence of immunoreactive cell bodies in the mammillary bodies as also noted in sheep (Polkowska, 1986) and mouse (Livne et al., 1993) fetuses. The function of such a transient presence of $\mathrm{GnRH}$ neurones in the mammillary area is unknown.

With regard to the main target of the GnRH neurones in the control of gonadotrope function, the median eminence, it is noteworthy that the first immunoreactive fibres reach it as early as day 49 . Since both the anatomical development of the median eminence (Matwijiw et al, 1989) and the vascular hypothalamic-hypophyseal connections (Levidiotis et al., 1989) are fully completed at day 45, it can be hypothesized that these early fibres may already release some $\mathrm{GnRH}$ which acts on the developing pituitary, where gonadotrope cells have been immunohistochemically identified on day 50 (MessaoudToumi et al., 1993).

\section{Axonal sprouting of the developing GnRH neurones}

Putative GnRH-immunoreactive growth cones have been observed only during a restricted period in the development of rat fetuses (Tobet et al., 1992), suggesting that during later stages the peptide is 
(a)

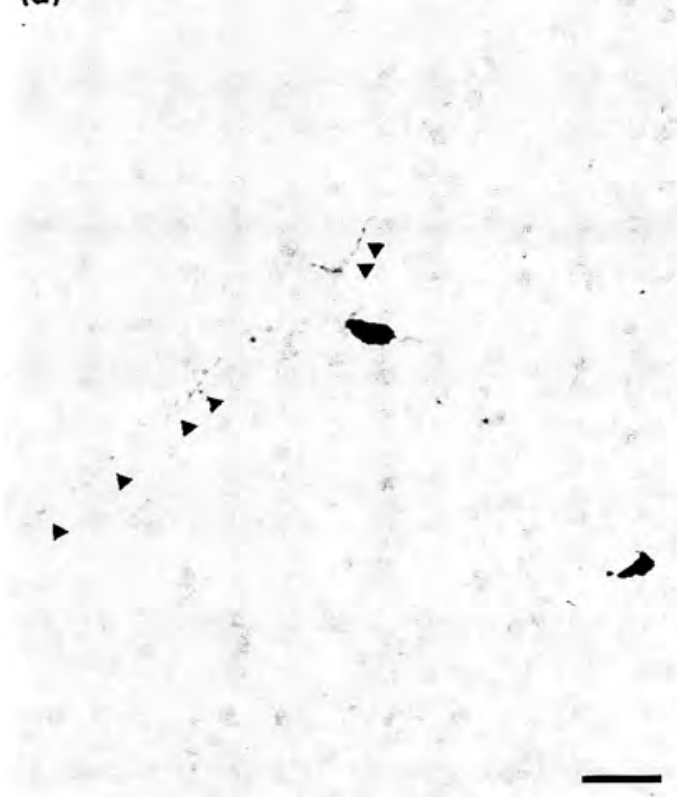

(c)
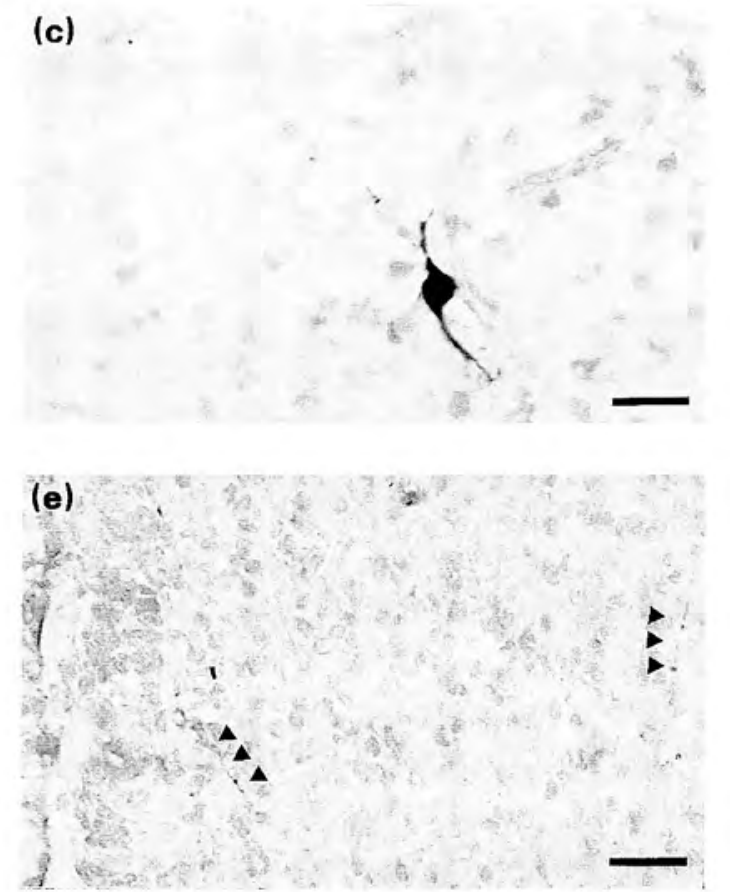

(b)

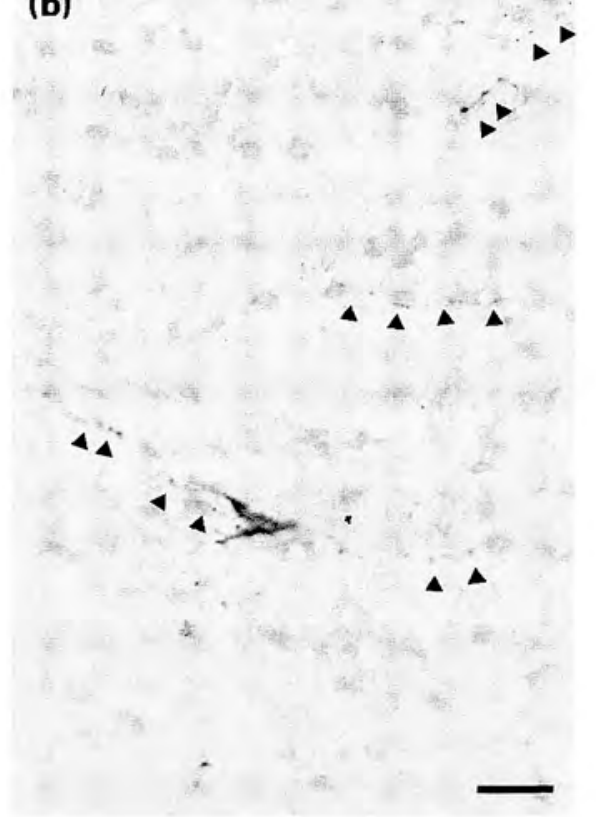

(d)

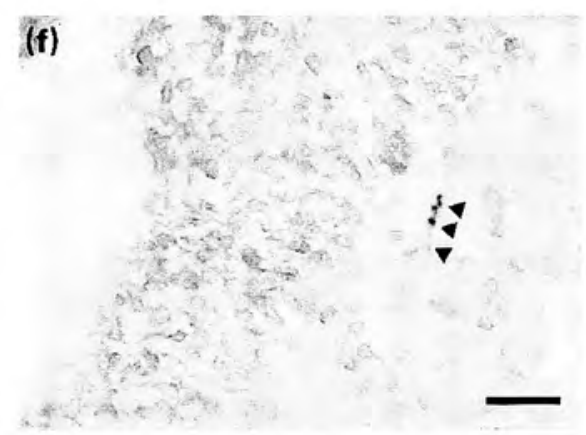

Fig. 6. Frontal cryostat sections from a day 60 sheep fetus were treated using the peroxidase-antiperoxidase method in the presence of Triton-X100. GnRH-immunoreactive perikarya are mainly labelled in the medial preoptic area (a), but also in the mediobasal hypothalamus (b) including its posterior part at the transition with the mammillary bodies (c), and in the mammillary bodies themselves, close to the floor of the diencephalon (d); very thin immunoreactive fibres, indicated by arrowheads, are found in the preoptic area (a), including the organum vasculosum of the lamina terminalis (e), in the mediobasal hypothalamus (b), and also in extra-preopticohypothalamic areas, such as the stria medullaris thalami at the level of the developing habenula (f). Scale bars represent $25 \mu \mathrm{m}$. 

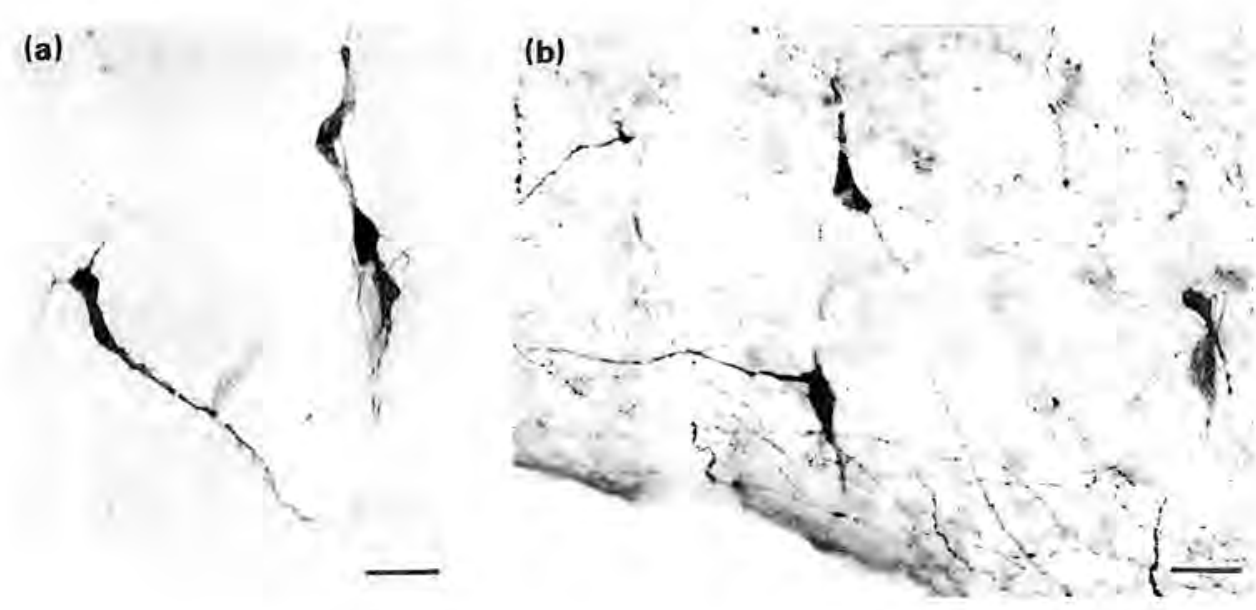

(c)

Fig. 7. In frontal free-floating sections from a fetus at day 75 (peroxidase-anti-peroxidase labelling), immunoreactive $\mathrm{GnRH}$ neuronal systems exhibit most of their adult characteristics: perikarya and fibres are both quite numerous in the mediobasal preoptic area (a), and also in the mediobasal hypothalamus (b) and they are also found in extra-preopticohypothalamic areas, such as the medial amygdala (c). Note that they display various morphologies. Scale bars represent $25 \mu \mathrm{m}$.

present only when the processes are extended. The presence of immunoreactive fibres in the nasal septum of monkey fetuses (Ronnekleiv and Resko, 1990), or associated with the nervus terminalis in sheep fetuses (see above) together with the presence of fibres containing the processed peptide in or close to the median eminence at a time when cell bodies are still migrating toward the preoptic area (our own results and those obtained in mouse fetuses (Livne et al., 1993)), also suggest that axonal growth, and thus differentiation, may occur very early during development. However, the previous data seem to indicate that the time when GnRH neurones initiate axonal outgrowth may be species specific

\section{Mechanisms involved in the intracerebral migration of GnRH neurones}

The presence of a CAM-trail associated with migrating $\mathrm{GnRH}$ neurones along the medial edge of the forebrain has been described in chicken embryos (Norgren and Brackenbury, 1993). Such a trail could guide the migrating neurones through homophylic interactions with glycoconjugates present on their surface. A glycoconjugate (CC2) is expressed on a subset of migrating GnRH neurones in the forebrain of the rat fetus (Tobet et al., 1992). The central pathway followed by the GnRH neurones through the forebrain towards the preoptic area corresponds to the central roots of the nervus terminalis (Johnston, 1913; Larsell, 1950; Wirsig and Leonard, 1986). In the preoptic area of one adult ewe, part of the GnRH 
Morphological maturation

Potential for ME secretion

Axonal sprouting and growth

Intracerebral migration

Origin and migration

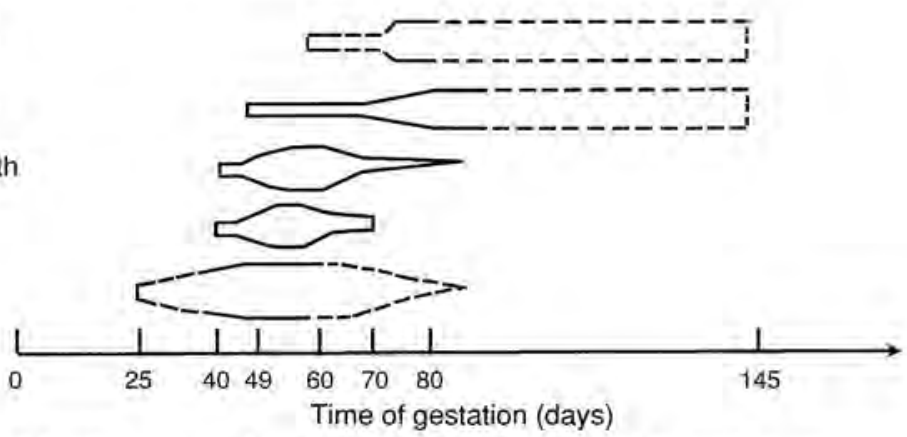

Fig. 8. Schematic ontogeny of GnRH neuronal development in the sheep fetus. ME; median eminence.

neurone population has been observed as forming a 'sort of nerve' (M. Caldani, M. Batailler, J. Fleming, unpublished data), suggesting a failure in the dispersion mechanism of the neurones out of the nervus terminalis. However, these data are too fragmentary to allow any reliable explanation for the intracerebral migration and dispersion of the $\mathrm{GnRH}$ neurones.

\section{Conclusion}

In the sheep fetus, even if the earliest steps of development remain unknown, the origin, migration and maturation of the GnRH neurones seem to occur in a similar way to those of other mammalian and non-mammalian species. The main characteristics of $\mathrm{GnRH}$ neuronal development in sheep fetuses (Fig. 8) are (i) the apparant delay in phenotypic differentiation, i.e. absence of $\mathrm{GnRH}$ immunoreactivity during the early migratory steps compared with that of mice, (ii) the short period required for the intracerebral dispersion and axonal growth of the $\mathrm{GnRH}$ neurones, including the early occurrence of immunoreactive fibres in the median eminence, and (iii) a morphological maturation completed around mid-gestation. Culture of olfactory placode explants in vitro could be a suitable model to study to obtain a better understanding of what happens at the level of the olfactory placode. Preliminary results obtained in our laboratory using fetal mouse or sheep olfactory placodes are very promising. Such a model could also be helpful for the study of both the migratory phenomenon and mechanisms underlying the regulation of $\mathrm{GnRH}$ expression and secretion.

The authors thank A. Locatelli for the surgery, A. Beguey and O. Moulin for their contribution in obtaining the illustrations and D. Nowak for the reviewing of the English manuscript.

\section{References}

Advis JP, Kuljis RO and Dey G (I985) Distribution of luteinizing hormone-releasing hormone (LHRH) content and total LHRH-degrading activity (LHRH-DA) in the hypothalamus of the ewe Endocrinology 116 2410-24I8

Akutsu S, Takada M, Ohkihamazaki H, Murakami S and Arai Y (1992) Origin of luteinizing hormone-releasing hormone (LHRH) netrons in the chick embryo-effect of the olfactory placode ablation Neuroscience Letters 142 241-244

Caldani M and Batailler M (1990) Presence of luteinizing hormone-releasing hormone in the sheep skin Neuroendocrinology 52 (Supplement 1) 56 (Abstract)

Caldani M. Batailler M and Jourdan F (1987) The sheep terminal nerve: coexistence of $\mathrm{LHRH}$ - and $\mathrm{AChE-containing}$ neurons Neuroscience Leffers $83221-226$
Caldani M, Batailler M, Thiéry JC and Dubois MP (1988) LHRH. immunoreactive structures in the sheep brain Histochemistry. 89 129-139

Caldani M, Caraty A, Pelletier J, Thiéry JC and Tillet Y (1993) L.H pulsatile release and its control Reproduction in Mammals and Man Pp 79-96 Eds C Thibault. MC Levasseur and RHF Hunter. Ellipses, Paris

Couly GF and Le Douarin NM (1988) The fate map of the cephalic neural primordium at the presomitic to the 3-somite stage in the avian embryo Development 103 (Supplement) 101-113

Daikoku S, Koide I, Chikamori-Aoyama M and Shimomura Y (1993) Migration of LHRH neurons derived from the olfactory placode in rats Archives of Histology and Cytology $56353-370$ 
Demski LS (1993) Terminal nerve complex Acta Anatomica $14881-95$

El Amraoui A and Dubois PM (1993) Experimental evidence for an early commitment of gonadotropin-releasing hormone neurons, with special regard to their origin from the ectoderm of nasal cavity presumptive territory Newroendocrinology $57991-1002$

Hayes WP, Wray S and Battey JF (1994) The frog gonadotropinreleasing hormone-1 (GnRH-1) gene has a mammalian-like expression pattern and conserved domains in GnRHassociated peptide, but brain onset is delayed until metamorphosis Endocrinology 134 1835-1845

Johnston JB (1913) Nervus terminalis in reptiles and mammals The joumal of Companative Neurology 23 97-120

Kallmann F, Schoenfeld WA and Barrera SE (I944) The genetic aspects of primary eunuchoidism American Joumal of Mental Deficiency 48 203-236

Larsell $O$ (1918) Studies on the nervus terminalis: mammals The Joumal of Comparative Neurology 30 3-68

Larsell O (1950) The nervus terminalis Annals of Otology, Rhinology and Laryngology (Saint Louis) 59 414-438

Legouis R, Hardelin JP, Levilliers J, Claverie JM, Compain S, Wunderle V, Millasseau P, Le Paslier D, Cohen D, Caterina D, Bougueleret L, Weissenbach J and Petit C (I991) The candidate gene for the X-linked Kallmann syndrome encodes a protein relatéd tó adhesion molecules Cell 67 $423-435$

Legouis R, Cohensalmon M, Delcastillo I and Petit C (1994) Isolation and characterization of the gene responsible for the $\mathrm{X}$ chromosome-linked Kallmann syndrome Biomedicine and Pharmacolherapy $48 \quad 241-246$

Lehman M, Robinson J, Karsch F and Silverman AJ (1986) Immunocytochemical localization of luteinizing hormonereleasing hormone (LHRH) pathways in the sheep brain during anestrus and the mid-luteal phase of the estrous cycle The Journal of Comparative Neurology 244 19-35

Leshin LS, Rund LA, Crim JW and Kiser TE (1988) Immunocytochemical localization of luteinizing hormone-releasing hormone and proopiomelanocortin neurons within the preoptic area and hypothalamus of the bovine brain Biology of Reproduction 39 963-975

Levidiotis ML, Wintour EM, McKinley MJ and Oldfield BJ (1989) Hypothalamic-hypophyseal vascular connections in the fetal sheep Neuroendocrinology 49 47-50

Livne I, Gibson MJ and Silverman AJ (1993) Biochemical differentiation and intercellular interactions of migratory gonadotropin-releasing hormone $(\mathrm{GnRH})$ cells in the mouse Developmental Biology $\mathbf{1 5 9}$ 643-656

Matwijiw I, Thliveris JA and Faiman C (1989) Hypothalamopituitary portal development in the ovine fetus Biology of Reproduction 40 1127-1130

Messaoud-Toumi LH, Taragnat C and Durand P (1993) Heterogeneity in the storage of gonadotropins in the ovine fetus and evidence for luteinizing hormone-follicle-stimulating hormone cells in the fetal pituitary Biology of Reproduction 48 1239-1245

Murakami S, Seki T, Wakabayashi K and Arai Y (1991) The ontogeny of luteinizing hormone-releasing hormone (LHRH) producing neurons in the chick embryo: possible evidence for migrating LHRH neurons from the olfactory epithelium expressing a highly polysialylated neural cell adhesion molecule Neuroscience Research 12 421-431

Murakami S, Kibuyama S and Arai Y (1992) The origin of the luteinizing hormone-releasing hormone ( $\mathrm{LHRH}$ ) neurons in newts (Cynops pyrrhogaster): the effect of olfactory placode ablation Cell and Tissue Research 269 21-27

Norgren RB and Brackenbury R (1993) Cell adhesion molecules and the migration of LHRH neurons during development Developmental Biology $160377-387$

Norgren RB and Lehman MN (1991) Neurons that migrate from the olfactory epithelium in the chick express luteinizing hormone-releasing hormone Endocrinology $12 \mathrm{~s}$ $1676-1698$

Northcutt RG and Muske LE (1994) Multiple embryonic origins of gonadotropin-releasing hormone $(\mathrm{GnRH}) \mathrm{immu-}$ noreactive neurons Developmiental Brain Research 78 $279-290$

Pellier V and Astic L. (1994) Histochemical and immunocytochemical detection of the migration of neurons from the rat olfactory placode Cell and Tissue Research 275 $587-598$

Polkowska J (1986) Ontogeny of luteinizing hormone releasing hormone (LHRH) and somatostatin (SRIF) in the hypothalamus of the sheep Folia Histochemian et Cytobiologica 24 195-202

Quanbeck CD, Sherwood NM, Millar RP and Terasawa E (1994) Neurons expressing a non-mammalian form of L.HRH originate from the olfactory placode and migrate into the brain priot to mammalian LHRH neurons in the Rhesus monkey Neuroendocrinology 60 (Supplement 1) 54 (Abstract)

Radovick S, Wray S, Lee E, Nicols DK, Nakayama Y, Weintraub BD, Westphal H, Cutier GB and Wondisford FE (1991) Migratory arrest of gonadotropin-releasing hormone neurons in transgenic mice Proceedings of the National Academy of Sciences USA 88 3402-3400

Ronnekleiv OK and Resko IA (1990) Ontogeny of gonadotropin-releasing hormone-containing neurons in early fetal development of Rhesus macaques Endocrinology $126498-511$

Rugarli El, Lutz B, Kuratani SC, Wawersik S, Borsani G, Ballabio A and Eichele G (1993) Expression pattern of the Kallmann syndrome gene in the olfactory system suggests a role in neuronal targeting Nature Genelics 4 19-26

Schwanzel-Fukuda M and Pfaff D (1989) Origin of luteinizing hormone-releasing hormone neurons Nature 338 $161-164$

Schwanzel-Fukuda M and Silverman AJ (1980) The nervus terminalis of the guinea pig; a new luteinizing hormonereleasing hormone neuronal system The Journal of Comparative Neurology 191 213-225

Schwanzel-Fukuda M, Bick D and Pfaff DW (1989) Luteinizing hormone-releasing hormone(LHRH)-expressing cells do not migrate normally in an inherited hypogonadal (Kallmann) syndrome Molecular Brain Research 6 $311-326$

Schwanzel-Fukuda M, Abraham S, Crossin KL, Edelman GM and Pfaff DW (1992a) Immunocytochemical demonstration of neural cell adhesion molecule (NCAM) along the migration route of luteinizing hormone-releasing hormone (LHRH) in mice The Journal of Comparative Neurology 321 I-18

Schwanzel-Fukuda M, Jorgenson KL, Bergen HT, Weesner GD and Pfaff DW (1992b) Biology of normal luteinizing hormonereleasing hormone neurons during and after their migration from olfactory placode Endocrine Revietos 13 623-634

Schwanzel-Fukuda M, Reinhard GR, Abraham S, Crossin KL Edelman GM and Pfaff DW (1994) Antibody to neural cell adhesion molecule can disrupt the migration of luteinizing 
hormone-releasing hormone neurons into the mouse brain The Joumal of Comparative Neurology 342 174-185

Silverman AJ, Livne I and Witkin JW (1994) The gonadotropinreleasing hormone $(\mathrm{GnRH})$, neuronal systerns: immunocytochemistry and in situ hybridization The Physiology of Reproduction (2nd Edn) pp 1683-1709 Eds E Knobil and JD Neill. Raven Press, New York

Terasawa E, Quanbeck CD, Schuly CA, Burich AJ, Luchansky LL and Claude P (1993) A primary cell culture system of luteinizing hormone releasing hormone neurons derived from embryonic olfactory placode in the Rhesus monkey Endocrinology 133 2379-2390

Tobet SA, Crandall JE and Schwarting GA (1992) Relationship of migrating luteinizing hormone-releasing hormone neurons to unique olfactory system glycoconjugates in embryonic rats Developmental Biology $155471-482$
Wirsig CR and Leonard CM (1986) The terminal nerve projects centrally in the hamster Neuroscience 19 709-717

Wood RI, Newman SW, Lehman MN and Foster DL (1992) GnRH neurons in the fetal lamb hypothalamus are similar in males and females Neuroendocrinology $\mathbf{5 5}$ 427-4.33

Wray S, Grant P and Gainer H (1989a) Evidence that cells expressing luteinizing hormone-releasing hormone mRNA in the mouse are derived from progenitor cells in the olfactory placode Proceedings of the National Academy of Sciences USA $\mathbf{8 6} 8132-8136$

Wray S, Nieburgs A and Elkabes S (1989b) Spatiotemporal cell expression of luteinizing hormone-releasing hormone in the prenatal mouse: evidence for an embryonic origin in the olfactory placode Developmental Brain Research 46 $309-318$ 